\title{
Glycemic Control and it's Associated Factors in Type 2 Diabetic Patients in Suhul Hospital, Northwest Tigray, Ethiopia
}

\section{Berhane Fseha*}

Institute of Public Health, College of Medicine and Health Sciences, University of Gondar, Ethiopia

\begin{abstract}
Introduction: Diabetic complication can be reduced by maintaining good glycemic control. The main goal in diabetic management is achieving good glycemic control because it reduces hospital admission due to diabetic related complication. However, majority of them did not achieve and needs contextual factor identification because the reasons for poor glycemic control in Type 2 diabetes are complex. The objective of this study was to assess the magnitude of poor glycemic control and its associated factors among type 2 diabetic patients at Suhul Hospital, Northwest Tigray, Ethiopia.

Methods: Hospital based cross sectional study was conduct on systematically sampled 200 type 2 diabetic patients with regular follow up. Data was collect by interviewing patients during hospital visits and measuring fasting blood glucose at the time of interview at the same time by reviewing the last two month fasting blood glucose results from their chart. Data collection took place from march to april 2014. Good glycemic control was defined as the three month average fasting blood sugar $(F B S)<126 \mathrm{mg} / \mathrm{dl}$. Binary logistic regression analysis was conduct to identify predictor of glycemic control.

Result: Patients had the mean age of $42.2 \pm$ SD 6.6 years, $68.5 \%$ were males, $71.5 \%$ were living in urban, $57 \%$ had diploma and above educational status, $36.5 \%$ achieve good glycemic control, FBS $<126 \mathrm{mg} / \mathrm{dl}, 66 \%$ of the patients had $<7$ year duration of diabetes. On multivariate logistic regression analysis, moderate physical exercise $(\mathrm{AOR}=2.927,95 \% \mathrm{Cl}=1.335-6.420)$ taking meal prescribed by their physician appropriately $(\mathrm{AOR}=2.568,95 \%$ $\mathrm{Cl}=1.222-5.398)$ and medication adherence $(\mathrm{AOR}=4.156,95 \% \mathrm{Cl}=1.835-9.409)$ were factors associated with good glycemic control.

Conclusion: This study reveals that the proportion of diabetic patients achieving good glycemic control was low. Moderate physical exercise, taking meal prescribed by their physician appropriately and medication adherence were factors associated with good glycemic control.
\end{abstract}

Keywords: Type 2 diabetes mellitus; Glycemic control; Fasting blood glucose

\section{Introduction}

Diabetes is a chronic disease that occurs when the pancreas does not produce enough insulin, or when the body cannot effectively use the insulin, it produces. Type 2 diabetes is a heterogeneous group of disorders characterized by variable degree of insulin resistance, impaired insulin secretion and increased glucose production [1].

The prevalence of diabetes in the year 2013 was $8.3 \%$ with 382 million people suffer from diabetes across the world and it projected to affect 592 million people by 2035. And Africa have more than 19 million diabetic patients with prevalence of $4.9 \%$ and in Ethiopia there were $1,852,230$ cases of diabetes in 2013 with $4.36 \%$ prevalence as per international diabetic federation 2013 [2].

Type 2 diabetes is much more common and account for over $90 \%$ in sub-Saharan Africa of all diabetes and it primarily affects adults $[3,4]$. Evidences show that achieving good glycemic control is main therapeutic goal for all diabetic patients to prevent organ and other micro vascular and macro vascular complications. Furthermore, complication of diabetes are preventable if the blood sugar maintain at optimum level [5-7].

There is no cure for this disease and it requires continuing medical care and achieving good glycemic control to prevent acute complications and to reduce the risk of long-term complications because poor glycemic control is the most common cause of hospital admissions and complications in diabetic patients [3]. However, majority of the diabetic patients did not maintain their blood glucose at optimum level. Hence, the factors that affect the glycemic control significantly should identify at the local level.

\section{Methods}

Hospital based cross sectional study was conducted on type 2 diabetic patients who had been attending outpatient clinic at suhul hospital. The study was conducted from march-April, 2014. All type 2 diabetic patients who are on follow up at outpatient clinic during the study period were the study population. There are 600 diabetic patients on follow-up among those 400 patients are type 2 diabetes.

\section{Sample size \& sampling procedures}

Using Single population proportion formula and the following assumptions sample size had been be determined.

*Corresponding author: Berhane Fseha, Institute of Public Health, College of Medicine and Health Sciences, University of Gondar, Ethiopia, Tel: 251910129815; E-mail: berhanefish@gmail.com

Received February 02, 2017; Accepted March 10, 2017; Published March 15 2017

Citation: Fseha B (2017) Glycemic Control and it's Associated Factors in Type 2 Diabetic Patients in Suhul Hospital, Northwest Tigray, Ethiopia. J Diabetes Metab 8 : 729. doi: 10.4172/2155-6156.1000729

Copyright: (c) 2017 Fseha B. This is an open-access article distributed under the terms of the Creative Commons Attribution License, which permits unrestricted use, distribution, and reproduction in any medium, provided the original author and source are credited. 


$$
\dot{m}=\frac{Z^{2}(p)(1-p)}{d^{2}}
$$

Where,

$\mathrm{z}=$ the reliability coefficient corresponding to $95 \%$ level of confidence $(\mathrm{z}=1.96)$.

$\mathrm{P}=$ proportion of diabetic patients who achieved good glycemic control was taken as a study, conducted in Mekelle, which is $32 \%$.

$\mathrm{W}=5 \%$ margin of error

By Substituting the values

$$
=\frac{1.96^{2}(0.32)(0.68)}{(0.05)^{2}}=334
$$

However, the study populations are less than 10,000; it needs correction formula for the final sample size

$$
\begin{array}{r}
\mathrm{nf}=\underline{\mathrm{ni}} \\
1+\underline{\mathrm{ni}} \\
\mathrm{N}
\end{array}
$$

$\mathrm{nf}=200,10 \%$ non-response rate was considered.

Systematic random sampling technique used. By dividing the sample size to the total population the sample interval was two. Using lottery method from one and two by random. Every other patient who came to the outpatient clinic was included in the study.

\section{Variables of the study}

Dependent variable: Glycemic control; Good (FBS 70-130 mg/dl), Poor (FBS $>130 \mathrm{mg} / \mathrm{dl})$.

Independent variables: 1) Scio demographic characteristics: age ,sex, marital status, educational status, wealth, BMI 2) Life style: alcohol consumption, physical exercise, traditional medication. 3) Clinical and self-managment: Co-morbidity other than diabetes, duration of diabetes, home glucose monitoring, medication adherence and drug utilization pattern.

\section{Operational definitions}

Glycemic control: It is managing blood glucose level of diabetic patients at optimum level. Good glycemic control is defined as the three month average fasting blood glucose $70-130 \mathrm{mg} / \mathrm{dl}$ and poor glycemic control is defined as the three month average fasting blood glucose $>130$ $\mathrm{mg} / \mathrm{dl}$ [8]. Wealth status: Wealth index was calculated using principal component analysis by collecting data on house hold assets.

Body Mass Index (BMI): Height-for-height was use to classify under-weight, normal, overweight, and obesity in adults:

$>$ Under-weight $<18.5 \mathrm{~kg} / \mathrm{m}^{2}$

$>\quad$ Normal $18.5-24.99 \mathrm{~kg} / \mathrm{m}^{2}$

$>$ Overweight $25-29.99 \mathrm{~kg} / \mathrm{m}^{2}$

$>$ Obese $\geq 30 \mathrm{~kg} / \mathrm{m}^{2}$

Taking meal prescribed by physician appropriately: Eating meal only that were ordered by their physician (food containing high fiber) were considered as taking the meal prescribed by physician appropriately where as if the diabetic patients were eating meal not allowed by physician (like sugar, honey, marmalade and cakes) they are considered as not taking the meal prescribed by physician appropriately.

\section{Alcohol consumption}

Alcohol consumption was defined as taking any alcoholic drink such as beer, wine, spirits, were Tela classified and coded as follows:

1. Never

2. Daily

3. 5-6 days per week

4. 1-4 days per week

5. 1-3 days per month

Physical exercise: Involve moderate-intensity activity that causes smaller increases in breathing or heart rate like (carrying or lifting light loads) for at least 10 minutes continuously.

Medication adherence: Medication adherence was measured using morisky four scale medication measurement.

\section{Inclusion and exclusion criteria}

Inclusion criteria: All type 2 diabetic patients who were on follow up on outpatient department at Suhul Hospital and greater than or equal to 18 years old patients were included in the study.

Exclusion criteria: Patients who were seriously ill and patients who did not fast overnight were excluded from the study.

\section{Data collection procedures}

After overnight fasting, one drop of blood from finger prick was added to senso card glucometer to measure fasting blood glucose using glucose oxidase method. Data on determinants of glycemic control had been collected by face to face interview using pre tested on $5 \%$ of the study participants structured questionnaire format by trained data collectors from march to April 2014. Orientation and supervision were performed to maintain data quality. Two Diploma holder laboratory technicians and one Bsc laboratory technician were involved in data collection. The principal investigator handled the overall coordination.

\section{Data processing and analysis}

The data was entered to EPI INFO version 3.5.3 and analyzed using SPSS version 20 statistical software. Descriptive statistics and logistic regression analysis were done and variables significant at bi-variant analysis $(P \leq 0.2)$ were entered to multivariate analysis and odds ratio was used as measure of strength of association between the dependent variable and co-variants. P-value less than 0.05 had been be used for identifying statistically significant variable at multivariate analysis.

\section{Ethical Consideration}

The ethical approval and clearance was obtained from institutional review board (IRB), College of Medicine and Health Science, University of Gondar. Official permission was obtained from the hospital administration of the study area. Objective of the study was clearly explained to the study participants before conducting the interview and informed consent was obtained from each participant.

\section{Result}

\section{Socio demographic characteristics of study participants}

Of the total 200 study participants, $68.5 \%$ were male and the mean age was 42.2 years $( \pm$ SD 6.6$)$ in the range of $22-60$ years. Majority 
(84.5\%) of the participants were married, $57.5 \%$ of the diabetic patients had diploma, and above educational status (Figure 1 and Table 1).

\section{Clinical and self management profile of Type 2 diabetic patients}

Two third of the study subjects had diabetes for $<7$ years and $68.5 \%$ of the participants did not have any additional chronic illness other than Type 2 DM. Majority (87\%) of the study participants take glibenclamide oral hypoglycemic anti diabetic drug. Three fourth (74.5\%) of the study participants did not take any traditional medicine for diabetic management as well as $61 \%$ of the patients adhere to their medication (Table 2)

\section{Life style profile of Type 2 diabetic patients}

More than two third (71.5\%) of the study participants consume alcohol and $45 \%$ of the patients do moderate physical exercise. $40.5 \%$ of the participants didn't take meal prescribed by their physician appropriately (Table 3).

\section{Distribution of Glycemic control in diabetic patients}

From the diabetic patients whose age were 38-47 years nearly onethird (34.2\%) achieved good glycemic control and only $30.2 \%$ of the study participant achieved good glycemic control from those who had chronic illness other than diabetes. Of the study participants who get their medical service free of charge, only $35.2 \%$ achieved good glycemic control (Table 4)

\section{Glycemic control and its associated factor of study participants}

The proportions of diabetic patients who achieved good glycemic control were 37\% (95\% CI 30.5-42.5). The independent variable marital status, occupation, education, wealth status, taking meal prescribed by physician appropriately, physical exercise, home glucose monitoring, medication adherence, duration of DM show significant association with good glycemic control in bivariate binary logistic regression analysis and entered in to multivariate binary logistic regression analysis. Accordingly, in the multivariate analysis three of them (physical exercise, taking meal prescribed by their physician appropriately, and medication adherence) showed significant association with good glycemic control at $5 \%$ level of significance (Table 5).

Participants who did moderate-intensity activity, that causes small increases in breathing or heart rate such as brisk walking (or carrying light loads] for at least 10 minutes were two times (AOR=2.033, 95\% $\mathrm{CI}=1.025-4.034)$ more likely to have good glycemic control as compared to patients who didn't do moderate moderate physical exercise.

The likelihood of having good glycemic control among participants who take meal prescribed by their physician appropriately were 2.5 ( $\mathrm{AOR}=2.529,95 \% \mathrm{CI}=1.267-5.046)$ times higher as compared to patients who did not take meal prescribed by their physician appropriately.

The study participants who adhere to medication were 3.7 times (AOR=3.760, 95\% CI=1.767-8.001) more likely to have good glycemic control as compared to participants who did not adhere to medication. Distribution of Glycemic control in Type 2 diabetic patients by sex and residence is $38.7 \%$ of the study participants who achieved good glycemic control were male and $37.8 \%$ who achieved good glycemic control were living in urban.

\section{Discussion}

The key finding in the present study was the magnitude of glycemic control among the Type 2 diabetic patients was found to be $37 \%$ and the results revealed that moderate physical exercise, taking meal prescribed by physician appropriately and medication adherence were identified as independent predictors of good glycemic control.

In diabetes mellitus management, the corner stone is achieving good glycemic control, which is essential to prevent short and longterm complications of diabetes. In this study, $36.5 \%$ of participants achieved good glycemic control. The present study is consistent with a study reported from Mekelle, Tigray [9], Jimma [10], Addis Ababa [11], and Hawaii [12]. The present finding is higher than a study reported from jimma [13]. This might be due to the three-months average fasting blood glucose used in the present study to classify the glycemic control as poor and good. However, in the study conducted in jimma, one point in time fasting blood glucose was measured to classify glycemic

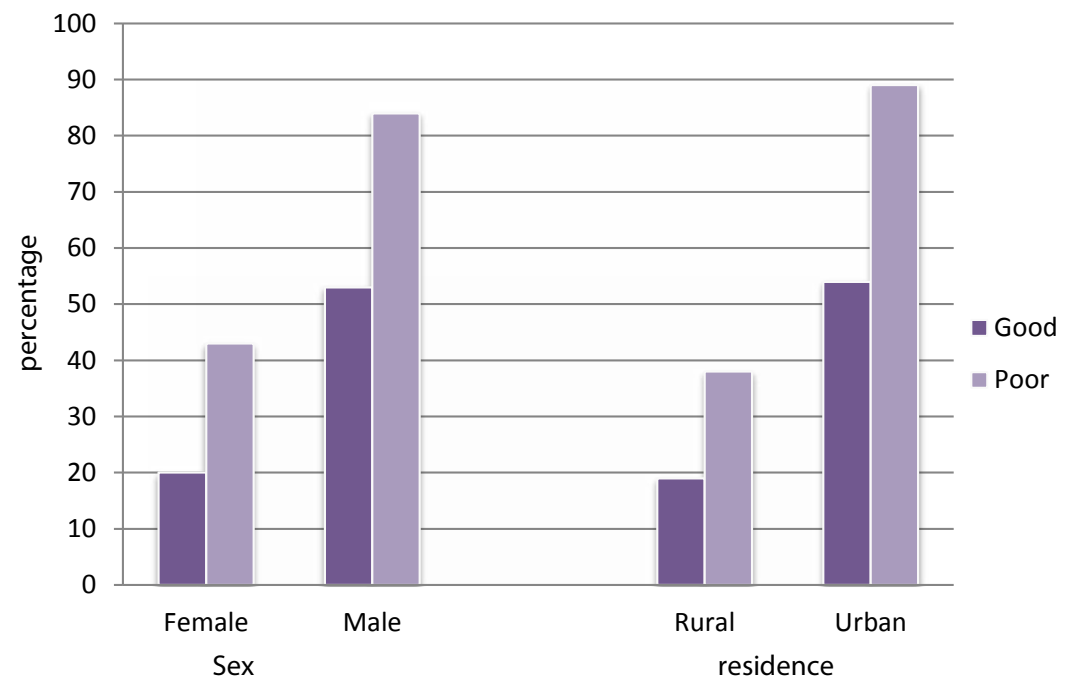

Figure 1: Distribution of glycemic control in type two diabetic patients by sex and residence in Suhul Hospital, North West Tigray, Ethiopia. 
Citation: Fseha B (2017) Glycemic Control and it's Associated Factors in Type 2 Diabetic Patients in Suhul Hospital, Northwest Tigray, Ethiopia. J Diabetes Metab 8: 729. doi: 10.4172/2155-6156.1000729

Page 4 of 6

\begin{tabular}{|c|c|c|}
\hline Variable & Frequency & Percentage \\
\hline \multicolumn{3}{|l|}{ Age (years) } \\
\hline $18-27$ & 4 & 2 \\
\hline $28-38$ & 46 & 23 \\
\hline $39-48$ & 117 & 58.5 \\
\hline $49-58$ & 28 & 14 \\
\hline$>58$ & 5 & 2.5 \\
\hline \multicolumn{3}{|l|}{ Sex } \\
\hline Male & 137 & 68.5 \\
\hline Female & 63 & 31.5 \\
\hline \multicolumn{3}{|l|}{ Marital status } \\
\hline Married & 169 & 84.5 \\
\hline Never married & 31 & 15.5 \\
\hline \multicolumn{3}{|l|}{ Educational status } \\
\hline No formal education & 63 & 31.5 \\
\hline Formal education & 137 & 68.5 \\
\hline \multicolumn{3}{|l|}{ Wealth } \\
\hline Poor & 70 & 35 \\
\hline Medium & 44 & 22 \\
\hline Rich & 86 & 43 \\
\hline \multicolumn{3}{|l|}{ BMI } \\
\hline Under weight & 9 & 4.5 \\
\hline Normal & 167 & 83.5 \\
\hline Overweight & 16 & 8 \\
\hline Obesity & 8 & 4 \\
\hline \multicolumn{3}{|l|}{ Service Care } \\
\hline With payment & 112 & 56 \\
\hline Free of charge & 88 & 44 \\
\hline
\end{tabular}

Table 1: Socio demographic characteristics of type 2 diabetic patients at Suhul Hospital, Northwest Tigray, Ethiopia. 2014.

\begin{tabular}{|c|c|c|}
\hline variable & Frequency & Percentage \\
\hline Alcohol consumption & & \\
\hline Never & 57 & 28.5 \\
\hline Daily & 18 & 21 \\
\hline 5-6 days per week & 42 & 26.5 \\
\hline 1-4 days per week & 52 & 15.5 \\
\hline 1-3 days per month & 31 & \\
\hline Physical activity & & 45 \\
\hline Yes & 90 & 55 \\
\hline No & 110 & \\
\hline Taking meal appropriately & & 59.5 \\
\hline Yes & 119 & 40.5 \\
\hline No & 81 & \\
\hline
\end{tabular}

Table 2: Clinical and self-management profile of Type 2 diabetic patients in Suhul Hospital, Northwest Tigray, Ethiopia 2014.

control of the patients and it included all types of diabetes and it could be study population. This study was for only Type 2 diabetic patients, but in jimma, the participants were only patients who were on insulin treatment and include Type 2 and Type 1 diabetes. This finding is lower than a study conducted in Jordan [14]; this might be due to the large sample size (533) and the method used for measuring glycemic control (Hbalc) in Jordan.

Moderate physical exercise was significantly associated with glycemic control and it was identified as one of the independent predictors of good glycemic control in the present study. Type 2 diabetic patients who did moderate physical exercise were 3 times more likely to achieve poor glycemic control than patients who did not do moderate exercise. The present study is inconsistent with that reported from other

studies from Jimma [15], Addis Ababa [16], East Africa Mozambique [17-22], Jordan [23,24] and India [25]. This is due to exercise, which has both short and long-term effects on carbohydrate metabolism in diabetic patients [26]. The physiologic response to exercise is modifying in diabetes, depending up on the serum insulin concentration at the time of exercise. Several factors contribute to this response like, exogenous insulin cannot shut off, there by maintaining muscle glucose uptake and inhibiting glucose output, the increased temperature and blood flow associated with exercise may speed insulin absorption from subcutaneous depots, resulting in higher serum insulin concentrations and the beneficial effect on glycemic control largely results from increased tissue sensitivity to insulin [27].

The patients who took meal prescribed by their physician appropriately were more than too likely to have good glycemic control than patients who did not take meal prescribed by their physician appropriately. Similar results were reported from Jordan [28]. This might be due to dietary modification which can improve many aspects of type 2 diabetics. Because, diet is considered as medical nutrition therapy by which the prescription is tailor for people with diabetes based on

\begin{tabular}{|c|c|c|}
\hline variable & Frequency & Percentage \\
\hline Alcohol consumption & & \\
\hline Never & 57 & 28.5 \\
\hline Daily & 18 & 9 \\
\hline 5-6 days per week & 42 & 21 \\
\hline 1-4 days per week & 52 & 26.5 \\
\hline 1-3 days per month & 31 & 15.5 \\
\hline Physical activity & & \\
\hline Yes & 90 & 45 \\
\hline No & 110 & 55 \\
\hline Taking meal appropriately & & \\
\hline Yes & 119 & 59.5 \\
\hline No & 81 & 40.5 \\
\hline
\end{tabular}

Table 3: Life style profile of Type 2 diabetic patients in Suhl Hospital, Northwest Tigre, Ethiopia 2014.

\begin{tabular}{|c|c|c|}
\hline variable & Frequency & Good Glycemic control n (\%) \\
\hline \multicolumn{3}{|l|}{ Age (years) } \\
\hline $18-27$ & 4 & $2(50)$ \\
\hline $28-38$ & 46 & $23(50)$ \\
\hline $39-48$ & 117 & $40(34.2)$ \\
\hline $49-58$ & 28 & $8(28.6)$ \\
\hline$>58$ & 5 & $0(0)$ \\
\hline \multicolumn{3}{|c|}{$\begin{array}{l}\text { Chronic illness other than } \\
\text { diabetes }\end{array}$} \\
\hline No & 63 & $19(30.2)$ \\
\hline Yes & 137 & $54(39.4)$ \\
\hline \multicolumn{3}{|l|}{ Current medication } \\
\hline Gilbenclamide & 174 & $66(37.9)$ \\
\hline Metformin & 23 & $6(26.1)$ \\
\hline Insulin & 3 & $1(33.3)$ \\
\hline \multicolumn{3}{|l|}{ BMI } \\
\hline Under weight & 9 & $1(11.1)$ \\
\hline Normal & 167 & $65(38.9)$ \\
\hline Overweight & 16 & $6(37.5)$ \\
\hline Obesity & 8 & $1(12.5)$ \\
\hline \multicolumn{3}{|l|}{ Service Care } \\
\hline With payment & 112 & $42(37.5)$ \\
\hline Free of charge & 88 & $31(35.2)$ \\
\hline
\end{tabular}

Table 4: Distribution of glycemic control by different variables among Type 2 diabetic patients in Suhul hospital, Northwest Tigray, Ethiopia. 
Citation: Fseha B (2017) Glycemic Control and it's Associated Factors in Type 2 Diabetic Patients in Suhul Hospital, Northwest Tigray, Ethiopia. J Diabetes Metab 8: 729. doi: 10.4172/2155-6156.1000729

Page 5 of 6

\begin{tabular}{|c|c|c|c|c|}
\hline \multirow[t]{2}{*}{ Variable } & \multicolumn{2}{|c|}{ Glycemic control } & \multirow[t]{2}{*}{$\operatorname{COR}(95 \%) \mathrm{Cl}$} & \multirow[t]{2}{*}{ AOR( $95 \% \mathrm{Cl})$} \\
\hline & Good,n(\%) & Poor, n(\%) & & \\
\hline \multicolumn{5}{|l|}{ Wealth status } \\
\hline Poor & $25(35.7)$ & $45(64.3)$ & \multicolumn{2}{|c|}{1} \\
\hline Medium & $24(54.5)$ & $20(45.5)$ & $2.160(1.001-4.660)$ & $2.335(0.933-5.844)$ \\
\hline Rich & $24(27.9)$ & $62(72.1)$ & $0.697(0.353-1.374)$ & $0.679(0.313-1.471)$ \\
\hline \multicolumn{5}{|l|}{ Educational status } \\
\hline No formal education & $18(28.6)$ & $45(71.4)$ & \multicolumn{2}{|c|}{1} \\
\hline Formal education & $55(40.1)$ & $82(59.9)$ & $1.677(0.880-3.195)$ & $1.054(0.492-2.261)$ \\
\hline \multicolumn{5}{|l|}{ Duration of DM } \\
\hline$<7$ year & $59(44.7)$ & $73(55.3)$ & \multicolumn{2}{|c|}{1} \\
\hline$\geq 7$ year & $14(20.6)$ & $54(79.4)$ & $0.321(0.162-0.634)$ & $0.460(0.214-1.987)$ \\
\hline \multicolumn{5}{|c|}{ Taking meal appropriately } \\
\hline No & $30(25.2)$ & $89(74.9)$ & 1 & \\
\hline Yes & $43(53.1)$ & $38(46.9)$ & $3.357(1.840-6.125)$ & $2.529(1.267-5.046)^{\star}$ \\
\hline \multicolumn{5}{|l|}{ Physical activity } \\
\hline No & $28(25.5)$ & $82(74.5)$ & \multicolumn{2}{|c|}{1} \\
\hline Yes & $45(50)$ & $45(50)$ & $2.929(1.614-5.313$ & $2.033(1.025-4.034)^{\star \star}$ \\
\hline \multicolumn{5}{|l|}{ Home glucose } \\
\hline \multicolumn{5}{|l|}{ Monitoring } \\
\hline No & $36(69.5)$ & $82(30.2)$ & 1 & \\
\hline Yes & $37(45.1)$ & $45(54.9)$ & $1.873(1.043-3.36)$ & $1.697(0.859-3.353)$ \\
\hline \multicolumn{5}{|l|}{ Medication adherence } \\
\hline No & $13(16.7)$ & $65(83.3)$ & 1 & \\
\hline Yes & $60(49.2)$ & $62(50.8)$ & 4.839 (2.419-9.67) & $3.760(1.767-8.001)^{\star * *}$ \\
\hline & & ${ }^{* *} p=0.042$ & & \\
\hline
\end{tabular}

Table 5: Bivariate and multivariate logistic regression analysis of glycemic control in Type 2 diabetic patients at Suhu Hospital, Northwest Tigray, Ethiopia 2014.

medical, life style, and personal factors and it is an integral component of diabetes management. Hence, the immediate effect of calorie restriction may be relating to depletion of hepatic glycogen stores, thereby reducing hepatic glucose output and the main determinant of fasting blood glucose $[29,30]$.

Medication adherence was identified as one of the independent determinants of glycemic control. Diabetic patients who adhere to medication were four times more likely to achieve good glycemic control as compared to patients who did not adhere to medication. The present study is inconsistent with study conducted in Jimma, Ethiopia [31] Tanzania [32], Jordan [33], Malaysia [34]. This could be due to most of the hypoglycemic agents used across the world had similar effect in gycemic control by decreased glucose production in the liver, increased insulin sensitivity and enhanced peripheral glucose uptake.

\section{Limitation of the Study}

It was conducted only among patients who were on follow up at outpatients clinic and hence may not be representative to the overall diabetic population. Hbalc was not measured due to unavailability in the hospital and even in the Tigray regional laboratory. The A1C test is a blood test that provides information about a person's average levels of blood glucose, also called blood sugar, over the past 3 months. However, the fasting blood glucose shows only point in time result of the diabetic patients.

\section{Conclusion and Recommendation}

\section{Conclusion}

The proportion of good glycemic control among the type 2 diabetic patients was low in this study. Moderate physical exercise, taking meal prescribed by their physician appropriately and medication adherence were associated with optimal level of glycemic control.

\section{Recommendation}

To Tigray Regional health bureau

$>$ Planning and preparing trainings for health care providers including diabetic patients about importance of physical exercise, taking meal prescribed by their physician appropriately and medication adherence to improve the glycemic status.

$>$ Involvement of health extension worker on diabetes management to optimize the glycemic control and prevents diabetic complications to Suhul Hospital, Media and concerned NGOs.

$>$ Preparing education on managing glycemic control and associated factors for diabetic patients using easily understandable methods.

$>$ Media and Non-Government Organizations should be involved on the importance of the determinants of glycemic control to achieve the targeted glycemic control for the diabetic patients. To researchers using Hbalc measurement are recommended to confirm this low good glycemic control finding.

\section{References}

1. Fauci AS, Braunwald E, Kasper DL (2008) Harrison Principles of Interna Medicine 17th edn. New York NY: McGraw Hill Medical 23: 949-956.

2. International Diabetes Federation (2013) IDF global guidline for Managing older people with type 2 diabetes. Brussels Belgium 13: 16-22. 
Citation: Fseha B (2017) Glycemic Control and it's Associated Factors in Type 2 Diabetic Patients in Suhul Hospital, Northwest Tigray, Ethiopia. J Diabetes Metab 8: 729. doi: 10.4172/2155-6156.1000729

Page 6 of 6

3. Mooradian (2003) Cardiovascular disease in type II diabetes mellitus. Current management guidelines. Arch Intern Med 163: 33-40.

4. Hall (2011) Diabetes in Sub Saharan Africa 1999-2011. Epidemiology and public health implications. BMC Public Health 11: 564.

5. Kasper L (2008) Harrison's principle of internal medicine. Graw Hill Company 17: 2275.

6. Akbar D, Al-Gamdi A (2000) Common causes of admission in diabetics. Saudi Med J 21: 539.

7. Rhee (2005) Patient adherence improves glycemic control. Diabetes Educator 31: 240.

8. Sjaugi M (2009) Success and opportunities for population-based prevention and control. Centers for Disease Control and Prevention 20: 29-42.

9. Zimmet $P$ (2001) Global and societal implications of the diabetes epidemic Diabetic Association 414: 782.

10. Juarez D (2012) Factors Associated With Poor Glycemic Control or Wide Glycemic Variability Among Diabetes Patients in Hawaii. Prev Chronic Disease 20: 9-12.

11. Al-Akour N (2011) Glycemic Control and Its Determinants among Patients with type 2 Diabetes Mellitus Attending a Teaching Hospital. J Diabetes Metab $2 \cdot 129$.

12. Khattab M (2010) Factors associated with poor glycemic control among patients with Type 2 diabetes in Jordan. J Diabetes Compli Jordan 24; 84-89.

13. Theng $C$ (2013) Poor glycemic control in younger women attending Malaysian public primary care clinics. findings from adults diabetes control and management registry. BMC Family Practice 14: 188.

14. Viswanathan M (2013) Current Glycemic Status and Diabetes Related Complications among Type 2 Diabetes Patients in India. Diabetes Metabol 6 : 61-72.

15. Padma K (2012) Evaluation of knowledge and self practices in diabetic patients and their role in disease management. National J Commu Med 3: 1.

16. Angamo M (2013) Determinants of Glycemic Control among Insulin Treated Diabetic Patients in Southwest Ethiopia. Glycemic Control 13: 23.

17. Nasir T (2012) Medication adherence in diabetes mellitus and self management practices among type-2 diabetics in Ethiopia. BMC 12: 15-20.

18. Yonas M (2012) Dyslipidemia Associated with Poor Glycemic Control in Type 2 Diabetes Mellitus and the Protective Effect of Metformin Supplementation. Protective Agency 22: 26-33.
19. GILL G (2009) Diabetic complications and glycaemic control in remote North Africa. Diabetes Int 15: 18-23

20. Johannsen N (2013) Determinants of the Changes in Glycemic Control with Exercise Training in Type Diabetes. PLoS ONE 8: 629-673.

21. Gilmer T (2005) Predictors of health care costs in adults with diabetes. Diabetes Care 28: 59-64.

22. Shetty S, Secnik K (2005) Oglesby AK. Relationship of glycemic control to total diabetes related costs for managed care health plan members with type 2 diabetes. J Manag Care Pharm 110: 559-564.

23. Oglesby A (2006) The association between diabetes-related medical costs and glycemic control. A Retrospective Analysis 4:1.

24. Khattab M (2013) Factors associated with poor glycemic control among patients with Type 2 diabetes in Jordan. J Diabetes Compli Jordan 24: 84-89.

25. Nur Sufiza A (2013) Factors associated with good glycemic control among patients with type 2 diabetes mellitus. J Diabetes Invest 21: 26-33.

26. Godfrey M (2014) Adherence to anti-diabetic drugs among patients with Type 2 diabetes mellitus. The Pan Afr Med J 17: 252.

27. Huimin Y (2014) Effect of Aerobic Training on Glucose Control and Blood Pressure in T2DDM East African Males. Hindawi Publishing Corporation 16 $15-19$.

28. Hailu E (2012) Self-care practice and glycaemic control amongst adults with diabetes at the Jimma University Specialized Hospital in south-west Ethiopia. A cross-sectional study. Afr J Prm Health Care Fam Med 4: 21.

29. Kidanu Berhe K, Bayeray Kahsay A, Berhe Gebru H (2013) Adherence to Diabetes Self-Management Practices among Type II Diabetic Patients in Ethiopia. Greener J Med Sci 3: 16.

30. Bureau TRH (2012) Tigray regional health Bureau first quarter report. Mekelle 20: 12.

31. Behan KJ (2011) New American diabetic association guidline for diagnosis and screening of diabetes. Adv Adm Lab 4: 20-22.

32. Colberg S (2010) Exercise and type 2 diabetes; the American College of Sports Medicine and the American Diabetes Association. Diabetes Care 33: 147.

33. Fang Z (2005) Determinants of exercise capacity in patients with type 2 diabetes. Diabetes Care 28: 1643.

34. Bantle JP, Wylie-Rosett J (2008) American Diabetes Association. Nutrition recommendations and interventions for diabetes. Diabetes Care 20: 18-26. 